\title{
Predictors of colorectal cancer screening prior to implementation of a large pragmatic trial in federally qualified healthcare centers
}

\author{
Amanda F. Petrik, MS ${ }^{1}$, Thuy Le, MPH ${ }^{2}$, Erin Keast, MPH $^{1}$, Jennifer Rivelli, MA ${ }^{1}$, Keshia \\ Bigler, $\mathbf{M P H}^{4}$, Beverly Green, $\mathbf{M D}^{3}$, William M. Vollmer, $\mathbf{P h D}^{1}$, and Gloria Coronado, $\mathbf{P h D}^{1}$ \\ The Center for Health Research, Kaiser Permanente Northwest, 3800 North Interstate Avenue, \\ Portland, Oregon 97227
}

OCHIN, 1881 SW Naito Pkwy, Portland, Oregon, 97201

Group Health Research Institute, 1730 Minor Ave \#1600, Seattle, Washington, 98101

Pacificsource, Bend, Oregon

\begin{abstract}
Background-Colorectal cancer screening can prevent cancer deaths. Federally qualified healthcare centers serve a unique patient population that often is not screened. Knowing who in this environment is getting screened via fecal testing and via colonoscopy can assist in tailoring intervention to raise rates of colorectal cancer screening.
\end{abstract}

Methods-We examined patient-level and neighborhood-level characteristics associated with being up to date with colorectal cancer screening guidelines. We also examined associations between these factors and being screened with a fecal test.

Results-We observed an increase in colorectal cancer screening rates from 2010 to 2015. Adjusted analyses revealed that the following factors were significantly associated with colorectal cancer screening: aged 65 or older, having any type of insurance, previous outpatient visits, and current or other preventive screenings. Among adults aged 50-75 who were up to date with colorectal cancer screening, factors associated with use of fecal testing, as opposed to colonoscopy, were: being younger, speaking a non-English language, being uninsured, having prior office visits, and having had a flu shot in past year.

Conclusion-Our findings may inform clinic-based effort to raise rates of colorectal cancer screening, especially in the community clinic setting.

\section{Keywords}

Colorectal cancer screening; fecal testing; colonoscopy; community health

\footnotetext{
Amanda F. Petrik, MS, Senior Research Associate, Center for Health Research, Kaiser Permanente Northwest, 3800 N. Interstate Avenue, Portland, Oregon 97227, 503-335-2483, Amanda.f.petrik@kpchr.org.

Trial Registration: ClinicalTrials.gov NCT01742065

Conflict of Interest:

The authors declare that they have no conflict of interest.
} 
Colorectal cancer (CRC) is the second leading cause of cancer death. An estimated 135,000 individuals will be diagnosed with CRC, and 50,000 will die from CRC in 2017(1). Screening can play an important role in reducing burden from this disease(2-4) because early detection and treatment can prevent unnecessary cancer death and prolong the lives of patients when cancers are found at earlier stages. A major effort is underway to increase CRC screening in the United States.(5) The American Cancer Society and the National Colorectal Cancer Roundtable have worked with more than 1,000 organizations to make the " $80 \%$ by 2018 " pledge.(5) This is a movement in which organizations commit to working toward the shared goal of screening 80\% of Americans for colorectal cancer by 2018. Underserved populations, which historically have had lower screening rates, are a major target of these increased screening efforts.

Currently, the United States Preventive Services Task Force (USPSTF) strongly recommends (Grade A) that adults aged 50-75 complete regular CRC screening. The most commonly used CRC screening tests in the US are colonoscopy (recommended every 10 years) and fecal testing with high sensitivity guaiac or fecal immunochemical (FIT) test (recommended annually). Patient preferences for these tests may be driven by access (availability, insurance coverage), and social factors (costs, cultural norms) as well as by other pros and cons of each modality (invasiveness, frequency of screening).

Access and social factors may also account for lower uptake of CRC screening tests among patients who receive care at federally qualified healthcare centers (FQHCs).(6-8) Such individuals are largely uninsured or on Medicaid, predominantly non-white, and often have low education and income. In order to reach the $80 \%$ screening target by 2018 , interventions that directly target these priority populations are needed.

The Strategies and Opportunities to Stop Colorectal Cancer in Priority Populations (STOP CRC) study is a large pragmatic trial that tests the implementation of health care systembased approaches to improve CRC screening rates in FQHCs through the use of FIT testing. (9) STOP CRC uses electronic health record (EHR) resources to optimize guideline-based screening in clinics whose patient populations have disproportionately low CRC screening rates.(9) Patients at those clinics who were not current for CRC screening were targeted with interventions designed to increase screening rates. Interventions included an introductory letter, a mailed fecal test, a reminder letter, and a Plan-Do-Study-Act (PDSA) cycle to further increase screening rates.

Prior research has indicated that factors including higher education, higher income, consistent health care patterns, male gender, and having insurance of any kind predict the likelihood of obtaining CRC screening.(10-14) However, additional information on individual- and community-level factors that predict screening rates is needed in order to tailor behavioral interventions to specific communities to increase access to CRC screening.

Social determinants of health (SDH) are non-medical factors that influence disease risks and outcomes. $(15,16) \mathrm{SDH}$ include community-level factors that reflect living conditions and social context, as well as individual-level factors such as race, ethnicity, and household 
income. If documented, discussed, and addressed, SDH data can be used to facilitate disease prevention. Patient-level SDH data can help providers make targeted recommendations that are sensitive to a patient's specific circumstances. Community-level SDH data can be used to identify social and environmental barriers to screening, which can then be addressed through targeted interventions.(17) Understanding SDH in the context of analyzing health outcomes is important when designing programs that can improve health outcomes.(18)

Using data collected as part of the STOP CRC study, we identified individual- and community-level characteristics that predicted whether patients who were CRC screening compliant, and hence excluded from the STOP CRC intervention. We also identified characteristics that predicted mode of screening among screened patients. Identifying these characteristics will allow for better targeting of screening programs and outreach efforts.

\section{Methods}

Design of the STOP CRC project has been described elsewhere.(9) The study population consisted of 31,287 eligible patients between the ages of 50-74 and were seen for an office visit at a participating community health center between $1 / 1 / 2013$ and 12/31/2013. Patients were excluded if they had history of colorectal cancer, inflammatory colitis, End Stage Renal Disease, or a total colectomy. All levels of insurance coverage were represented in the sample: $30.9 \%$ of participants were uninsured, $26.2 \%$ were on Medicaid, $27.4 \%$ were on Medicare, and $15.4 \%$ had commercial health insurance.

\section{Data sources}

Screening information and individual-level variables were obtained from electronic health record (EHR) data from 26 Community Health Center (CHC) sites in Oregon and California that were part of the STOP CRC study. All participating CHCs were part of OCHIN, a nonprofit health care controlled network that provides centrally hosted EHR services to more than 460 CHCs in 18 states. Community-level variables for each CHC were obtained from the ADVANCE Clinical Data Research Network (19). Community-level variables were collected at the tract level for all variables except for Emergency Department (ED) visits per 1,000 enrollees, this was collected at the county level.

\section{Variables}

Completion of a FOBT/FIT or colonoscopy was determined through lab results and health maintenance updates in the EHR.CRC screening compliance was defined as not having received fecal testing in the past 12 months, flexible sigmoidoscopy within the past 5 years, or normal colonoscopy within the last 10 years as of 1/1/2014. Among those who were compliant, patients were categorized into those who used FOBT/FIT (including FOBT/FIT followed by a confirmatory colonoscopy) versus colonoscopy alone.

Independent variables included data at the following levels: 1) patient (age, gender, race, ethnicity, language, household income); 2) encounter (patient's insurance status, number of office visits in the past year, types of chronic health conditions, and other screenings); and 3) community (GINI coefficient as a measure of income inequality, percent of unemployment, percent of persons with a bachelor's degree or higher, population density, 1-mile access to a 
supermarket or large grocery store, urban/rural designation, and number of ED visits per 1,000 enrollees).

\section{Analysis}

We used a generalized estimating equation (GEE) logistic regression model to assess the relationship between the variables of interest and screening compliance. The logistic regression test was used to calculate p-values for univariate models and the score tests was used to calculate $\mathrm{p}$-values for multivariate models. This method accounts for multiple visits nested within patients. We used the same method to analyze factors associated with FOBT/FIT use among those who were up to date with screening. Variables that were significant at the 0.20 level in univariate analyses were included in an initial multivariate model, then reverse stepwise selection was used to remove variables until all variables in the model were significant at $\mathrm{p}<0.05$. Next, adjusted models were created that accounted for correlation within clinics: assuming an independent correlation structure; we applied a robust sandwich variance estimator to account for possible model misspecification. Analyses were conducted using PROC GENMOD in SAS version 9.4 (SAS Institute Inc., Cary NC).

\section{Results}

Across 26 clinics, we identified 31,287 patients with at least one clinic visit in 2013. Of them, 10,381 patients were CRC screening compliant on 1/1/2014. The proportion of patients screened in a year increased from $17.7 \%$ in 2010 to $46.8 \%$ in 2015 , across all eligible patients (Figure 1). The proportion of all patients who received screening by FIT/ FOBT increased from $11.3 \%$ in 2010 to $28.4 \%$ in 2015, and the proportion who received screening by colonoscopy increased from $7.3 \%$ to $21.0 \%$. in the same period. Of the 10,381 patients who were up-to-date in their CRC screening, $42.7 \%$ were up-to-date because of prior fecal testing (including patients with a colonoscopy as follow-up to a positive fecal test) as opposed to colonoscopy only.

Factors associated with screening compliance are described in Table 1. Age was the only individual-level characteristic that significantly predicted screening compliance in the adjusted model: older adults (ages 65-74) were significantly more likely to be compliant than younger adults (ages 50-64). Encounter-level characteristics that predicted screening compliance included insurance status (rates ranged from $22.5 \%$ for uninsured patients to $39.3 \%$ for patients with Medicare), number of office visits in the past year (rates ranged from $21.4 \%$ for those with 1 visit to $45.2 \%$ for those with 6 or more visits), and having received prior preventive care, such as Pap testing, mammography, and flu shots. At the community level, no community-level variables persisted in the adjusted models.

Factors associated with FOBT/FIT use in the screening compliant group are described in Table 2. Individual-level characteristics that predicted screening by FIT/FOBT included age (44.5\% for those aged 50-64 vs. 37.6\% for those aged 65-75) and language (71.9\% for Spanish speakers vs. $37.3 \%$ for English speakers). Encounter-level characteristics that predicted screening by FIT/FOBT included insurance status (ranging from $28.5 \%$ for those with commercial insurance to $65.5 \%$ for the uninsured), number of office visits in the past year (ranging from $37.8 \%$ for 1 office visit to $43.1 \%$ for $6+$ office visits), and not receiving a 
flu shot in the last year ( $44.3 \%$ vs. $40.6 \%$ who did receive a shot). Again, no communitylevel variables persisted in the adjusted models.

\section{Discussion}

While CRC screening rates are increasing, more progress is needed to eliminate disparities and further reduce cancer burden. We sought to understand screening patterns in community clinics to better address barriers and challenges to increasing CRC screening. We identified several factors associated with screening compliance, and with use of FIT/FOBIT in screening, for $\mathrm{CHC}$ patients in Oregon and California.

Several encounter-level factors (insurance status, frequency of office visits, and prior screenings) were associated with being up-to-date with screenings. Knowledge of these associations can lead to clinical practices that target the specific needs of these patients. For example, knowing that uninsured patients are less likely to be screened opens an opportunity for providers to address benefits and barriers to CRC screening during an encounter. Further, understanding that having more office visits increases the likelihood of screening underscores the need to address CRC screening during a single office visit with patients who are not high utilizers, or to find other means, such as mailed FIT test programs, to address screening outside of office visits. Finally, given that patients who have other preventive care/ screenings are more likely to have CRC screening, systems can specifically target patients without other preventive care in screening programs.(19)

The use of FIT/FOBT has been shown to increase screening among underscreened populations.(20) In this study, we found higher rates of FIT/FOBT use, relative to colonoscopy, among patients who were younger, uninsured, and Spanish-speaking. Screening by FIT can be more accessible for patient's due to the simplicity of the test and the removal of barriers that are common to colonoscopy completion (e.g., missed work, necessary bowel preparation). However, attention needs to be paid to ensure that colonoscopies following an abnormal FIT result are being completed.(21)

The predictors of screening in the FQHC population are important for communities that are trying to increase screening among priority populations. Examining community vital signs can help us understand unscreened populations. Although none of our community level variables remained in the adjusted models, social determinants of health and communitylevel data are an important part of the story, but additional exploration is required to further understand screening deficiencies to increase screening.

Strengths of this study include our ability to describe trends in CRC screening rates over several years in a large FQHC patient population, and our ability to assess communityrelated factors alongside encounter-level and individual-level factors. One limitation was that we were unable to include or describe patients without a recent visit to the clinic. Based on the patterns seen here, we could expect patients who did not have a recent visit to have even lower screening rates than those seen here. Additionally, we assessed screening from the medical record, and not from self-report. Because colonoscopies are not always adequately reported in the EHR,(22) we are likely underestimating screening rates in our sample. 
However, we would not expect reporting errors to differ by the factors of interest here, so the patterns we report are unlikely to be affected by this underestimation. By focusing our analysis on $\mathrm{FQHCs}$, our findings provide insight into screening patterns amongst at risk populations, and are of particular relevance to heath care providers serving those populations. However, findings may not be generalizable to health care settings serving different patient populations.

We found that the most socially disadvantaged groups, specifically the uninsured, unemployed, and non-English speakers were more likely to complete fecal testing rather than colonoscopy. This suggests that programs that encourage FIT/FOBT use amongst these populations may be able to gain traction where efforts to encourage colonoscopies may not, and thus have the potential to dramatically reduce disparities in CRC screening. In general, targeting screening efforts to the specific needs and barriers faced by the $\mathrm{FQHC}$ population may increase screening rates, decrease disparities, and ultimately improve CRC outcomes.

\section{Acknowledgments}

Research reported in this publication was supported by the National Cancer Institute of the National Institutes of Health under Award Number UH3CA188640. The content is solely the responsibility of the authors and does not necessarily represent the official views of the National Institutes of Health.

\section{References}

1. Colorectal Cancer Facts \& Figures 2017-2019. American Cancer Society; Atlanta, GA: 2017.

2. U.S. Department of Health and Human Services Health Resources and Services Administration. [Accessed 06/09/2016] Colorectal Cancer Screening. http://www.hrsa.gov/quality/toolbox/ measures/colorectalcancer/index.html

3. Centers for Disease Control and Prevention (CDC). Vital signs: Colorectal cancer screening test use--United States, 2012. MMWR Morb Mortal Wkly Rep. 2013; 62(44):881-8. [PubMed: 24196665]

4. Centers for Disease Control Prevention. Cancer screening - United States, 2010. MMWR Morb Mortal Wkly Rep. 2012; 61(3):41-5. [PubMed: 22278157]

5. National Colorectal Cancer Roundtable. Tools \& Resources $-80 \%$ by 2018.2016

6. Sarfaty M, Doroshenk M, Hotz J, et al. Strategies for expanding colorectal cancer screening at community health centers. CA: a cancer journal for clinicians. 2013; 63(4):221-31. DOI: 10.3322/ caac.21191 [PubMed: 23818334]

7. Davis TC, Rademaker A, Bailey SC, et al. Contrasts in rural and urban barriers to colorectal cancer screening. Am J Health Behav. 2013; 37(3):289-98. DOI: 10.5993/ajhb.37.3.1 [PubMed: 23985175]

8. Klabunde CN, Cronin KA, Breen N, Waldron WR, Ambs AH, Nadel MR. Trends in colorectal cancer test use among vulnerable populations in the United States. Cancer Epidemiol Biomarkers Prev. 2011; 20(8):1611-21. DOI: 10.1158/1055-9965.epi-11-0220 [PubMed: 21653643]

9. Coronado GD, Vollmer WM, Petrik A, et al. Strategies and Opportunities to STOP Colon Cancer in Priority Populations: Design of a cluster-randomized pragmatic trial. Contemp Clin Trials. 2014; 38(2):344-9. DOI: 10.1016/j.cct.2014.06.006 [PubMed: 24937017]

10. Seeff LC, Nadel MR, Klabunde CN, et al. Patterns and predictors of colorectal cancer test use in the adult U.S. population. Cancer. 2004; 100(10):2093-103. DOI: 10.1002/cncr.20276 [PubMed: 15139050]

11. Beydoun HA, Beydoun MA. Predictors of colorectal cancer screening behaviors among averagerisk older adults in the United States. Cancer Causes Control. 2008; 19(4):339-59. DOI: 10.1007/ s10552-007-9100-y [PubMed: 18085415] 
12. Ioannou GN, Chapko MK, Dominitz JA. Predictors of colorectal cancer screening participation in the United States. Am J Gastroenterol. 2003; 98(9):2082-91. DOI: 10.1111/j. 1572-0241.2003.07574.x [PubMed: 14499792]

13. Halbert CH, Barg FK, Guerra CE, et al. Cultural, economic, and psychological predictors of colonoscopy in a national sample. J Gen Intern Med. 2011; 26(11):1311-6. DOI: 10.1007/ s11606-011-1783-9 [PubMed: 21732197]

14. Hudson SV, Ferrante JM, Ohman-Strickland P, et al. Physician recommendation and patient adherence for colorectal cancer screening. J Am Board Fam Med. 2012; 25(6):782-91. DOI: 10.3122/jabfm.2012.06.110254 [PubMed: 23136316]

15. Braveman P, Egerter S, Williams DR. The social determinants of health: Coming of age. Annual review of public health. 2011; 32:381-98. DOI: 10.1146/annurev-publhealth-031210-101218

16. World Health Organization. Social determinants of health. 2016

17. Bazemore AW, Cottrell EK, Gold R, et al. "Community vital signs": incorporating geocoded social determinants into electronic records to promote patient and population health. J Am Med Inform Assoc. 2016; 23(2):407-12. DOI: 10.1093/jamia/ocv088 [PubMed: 26174867]

18. DeVoe JE, Bazemore AW, Cottrell EK, et al. Perspectives in Primary Care: A Conceptual Framework and Path for Integrating Social Determinants of Health Into Primary Care Practice. Ann Fam Med. 2016; 14(2):104-8. DOI: 10.1370/afm.1903 [PubMed: 26951584]

19. Holden DJ, Harris R, Porterfield DS, et al. Enhancing the use and quality of colorectal cancer screening. Evidence report/technology assessment. 2010; (190):1-195. v.

20. Mehta SJ, Jensen CD, Quinn VP, et al. Race/Ethnicity and Adoption of a Population Health Management Approach to Colorectal Cancer Screening in a Community-Based Healthcare System. J Gen Intern Med. 2016; 31(11):1323-30. DOI: 10.1007/s11606-016-3792-1 [PubMed: 27412426]

21. Liss DT, Brown T, Lee JY, et al. Diagnostic colonoscopy following a positive fecal occult blood test in community health center patients. Cancer Causes Control. 2016; 27(7):881-7. DOI: 10.1007/s10552-016-0763-0 [PubMed: 27228991]

22. Petrik AF, Green BB, Vollmer WM, et al. The validation of electronic health records in accurately identifying patients eligible for colorectal cancer screening in safety net clinics. Fam Pract. 2016; doi: 10.1093/fampra/cmw065 


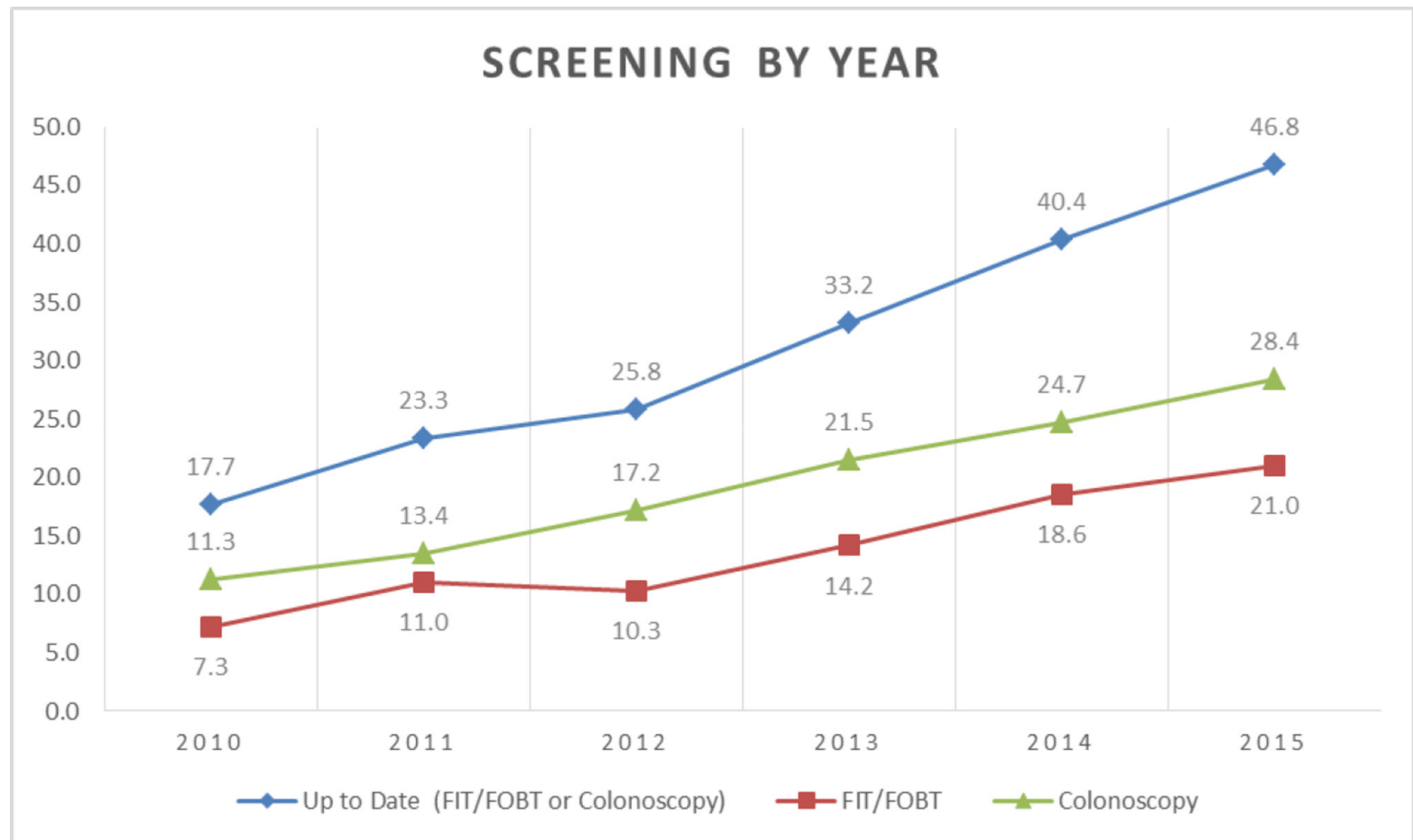

Figure 1.

Screening by year overall, by FIT/FOBT, and by Colonoscopy 
Table 1

Factors associated with being up-to-date for CRC screening at baseline by either FIT/FOBT or Colonoscopy

\begin{tabular}{|c|c|c|c|c|c|c|c|c|c|c|c|}
\hline \multirow{4}{*}{ Age } & \multirow{4}{*}{\begin{tabular}{l|}
$5-64$ \\
$65-74$
\end{tabular}} & \multirow{3}{*}{$\begin{array}{c}\text { Total } \\
24558 \\
\end{array}$} & \multirow{3}{*}{$\begin{array}{c}\begin{array}{c}\text { \% up to } \\
\text { date }\end{array} \\
31.5 \\
\end{array}$} & $\begin{array}{l}\text { Unadjusted } \\
\text { (SE not } \\
\text { cluster) }\end{array}$ & Adjusted* & \multirow{2}{*}{\multicolumn{2}{|c|}{ Other Screenings }} & \multirow{3}{*}{$\begin{array}{c}\text { Total } \\
8448 \\
\end{array}$} & \multirow{3}{*}{$\begin{array}{c}\begin{array}{c}\text { \% up to } \\
\text { date }\end{array} \\
39.4 \\
\end{array}$} & $\begin{array}{l}\text { Unadjusted } \\
\text { (SE not } \\
\text { cluster) }\end{array}$ & Adjusted \\
\hline & & & & \multicolumn{2}{|c|}{ Sig } & & & & & \multicolumn{2}{|c|}{ sig } \\
\hline & & & & \multirow{2}{*}{$<.0001$} & \multirow{2}{*}{0.0001} & \multicolumn{2}{|c|}{ Pap in past 3 years $(50-64)$} & & & \multirow{2}{*}{$<.0001$} & \multirow{2}{*}{0.0002} \\
\hline & & 6729 & 39.5 & & & & No & 9377 & 28.2 & & \\
\hline \multirow[t]{2}{*}{ Gender } & Female & 17825 & 33.5 & \multirow{2}{*}{0.1618} & \multirow{2}{*}{0.0014} & \multicolumn{2}{|c|}{ Mammograms in past 2 years } & 5348 & 48.4 & \multirow{2}{*}{$<.0001$} & \multirow{2}{*}{0.0017} \\
\hline & Male & 13462 & 32.8 & & & & No & 12477 & 27.1 & & \\
\hline \multirow[t]{3}{*}{ Ethnicity } & Hispanic & 3685 & 29.8 & \multirow{3}{*}{$<.0001$} & & Flu Sho & past YearY/N & 10156 & 44.2 & $<0001$ & $<0001$ \\
\hline & Non-Hispanic & 26849 & 33.9 & & & & No & 21131 & 27.9 & & . \\
\hline & Missing & 753 & 22.4 & & & Health & 1 & 4267 & 36.9 & & \\
\hline Language & English & 25649 & 33.1 & & & & 2 & 6618 & 50.0 & $<0001$ & \\
\hline & Spanish & 2853 & 29.3 & $<.0001$ & & & 3 & 3070 & 14.3 & & \\
\hline & Other & 2448 & 40.6 & & & & 4 & 2007 & 11.9 & & \\
\hline & Missing & 337 & 20.8 & & & & 5 & 2715 & 28.5 & & \\
\hline Race & White & 26581 & 32.4 & & & & 6 & 7543 & 34.7 & & \\
\hline & African American & 1540 & 37.0 & & & & 7 & 4002 & 31.1 & & \\
\hline & Asian American/ & 1654 & 45.0 & $<.0001$ & & & 8 & 1065 & 16.8 & & \\
\hline & & & & & & Community Vit & gns & & & & \\
\hline & Native American & 249 & 32.5 & & & GINI Income & 25 th quartile & 4867 & 32.9 & 5001 & \\
\hline & Mixed race/Other & 204 & 25.0 & & & Inequality & $50 \%$ quartile & 8195 & 35.6 & .0001 & \\
\hline & Unknown/Missing & 1059 & 29.6 & & & & $75 \%$ quartile & 4371 & 33.3 & & \\
\hline Insurance & Medicaid & 8212 & 36.6 & & & & Missing & 13854 & 31.8 & & \\
\hline & Medicare & 8584 & 39.3 & $<.0001$ & 0.0021 & Unemploy- & 25th quartile & 7852 & 37.9 & & \\
\hline & Uninsured & 9683 & 22.5 & & & ment & $50 \%$ quartile & 15305 & 31.8 & $<.0001$ & \\
\hline & Commercial & 4808 & 37.9 & & & & $75 \%$ quartile & 7735 & 31.2 & & \\
\hline Household & $<14,999$ & 13865 & 32.4 & & & & Missing & 395 & 30.9 & & \\
\hline & $15,000-29,000$ & 6039 & 30.5 & & & College & 25th quartile & 7886 & 27.8 & & \\
\hline & $30,000-44,999$ & 1590 & 35.2 & $<.0001$ & & & $50 \%$ quartile & 15215 & 35.4 & $<001$ & \\
\hline & $45,000-59,999$ & 520 & 47.1 & & & & $75 \%$ quartile & 7795 & 34.4 & 8001 & \\
\hline & $>60,000$ & 772 & 53.1 & & & & Missing & 391 & 30.7 & & \\
\hline & Unknown & 8501 & 33.3 & & & Pop & 25th quartile & 7764 & 31.5 & & \\
\hline Number of & 1 & 7810 & 21.4 & $<.0001$ & 0.0004 & Density & $50 \%$ quartile & 15391 & 33.3 & $<.0001$ & \\
\hline in Past Year & $2-5$ & 17003 & 34.0 & & & & $75 \%$ quartile & 7744 & 34.9 & & \\
\hline & $6+$ & 6474 & 45.2 & & & & Missing & 388 & 30.7 & & \\
\hline Chronic Healt & Conditions & & & & & 1 mile & Yes & 23964 & 33.3 & 05183 & \\
\hline & $\begin{array}{r}\text { Diabetes (Type II) } \\
\text { No }\end{array}$ & $\begin{array}{c}2970 \\
28317\end{array}$ & $\begin{array}{l}33.0 \\
332\end{array}$ & 0.8555 & & Access & No & 7323 & 32.9 & & \\
\hline & Depression & 6754 & 35.4 & & & Urban Rural & Rural & 7233 & 31.4 & & \\
\hline & No & 24533 & 32.6 & .0001 & & & Urban & 7194 & 42.7 & $<.0001$ & \\
\hline & Substance Abuse & 373 & 34.3 & & & & Cluster & 16860 & 29.9 & & \\
\hline & № & 30914 & 33.2 & 0.6400 & & ED Visits & 25th quartile & 10151 & 22.3 & & \\
\hline & & & & & & & $50 \%$ quartile & 13009 & 33.8 & $<.0001$ & \\
\hline & & & & correla & ure. & & $75 \%$ quartile & 8006 & 46.1 & & \\
\hline Dast 3 years, M. & mmograms in past $2 y$ & $\mathrm{~s}$, and $\mathrm{F}$ & Past & & & & Missing & 121 & 26.4 & & \\
\hline
\end{tabular}


Table 2

Factors associated with FOBT/FIT compared to colonoscopy use among those up-to-date for CRC screening

\begin{tabular}{|c|c|c|c|c|c|c|c|c|c|c|c|}
\hline & & \multirow[b]{2}{*}{$\begin{array}{c}\text { Total } \\
\text { Up to Date } \\
\end{array}$} & \multirow[b]{2}{*}{$\begin{array}{l}\text { \% Screened } \\
\text { by FIT }\end{array}$} & \begin{tabular}{|c|}
$\begin{array}{c}\text { Unadjusted } \\
\text { (SE not } \\
\text { cluster) }\end{array}$ \\
\end{tabular} & \multirow[t]{2}{*}{ Adjusted* } & \multirow{2}{*}{\multicolumn{2}{|c|}{ Other Screenings }} & \multirow[b]{2}{*}{$\begin{array}{c}\text { Total } \\
\text { Up to Date }\end{array}$} & \multirow[b]{2}{*}{$\begin{array}{l}\text { \% Screened } \\
\text { by FIT }\end{array}$} & $\begin{array}{l}\text { Unadjusted } \\
\text { (SE not } \\
\text { cluster) }\end{array}$ & Adjusted" \\
\hline & & & & & & & & & & \multicolumn{2}{|c|}{ Sig } \\
\hline \multirow[t]{2}{*}{ Age } & $50-64$ & 7726 & 44.5 & \multirow{2}{*}{0.0457} & & \multicolumn{2}{|c|}{ Pap in past 3 years $(50-64)$} & 3330 & 44.8 & 00040 & \\
\hline & $65-74$ & 2655 & 37.6 & & & & No & 2642 & 39.8 & 0.0042 & \\
\hline \multirow[t]{2}{*}{ Gender } & Female & 5972 & 42.6 & \multirow{2}{*}{0.2609} & & \multicolumn{2}{|c|}{ Mammograms in past 2 years } & 2587 & 36.1 & 80001 & \\
\hline & Male & 4409 & 42.9 & & & $(30-14)$ & No & 3385 & 47.6 & 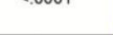 & \\
\hline \multirow[t]{3}{*}{ Ethnicity } & Hispanic & 1098 & 63.7 & \multirow{3}{*}{\multicolumn{2}{|c|}{$<.0001$}} & \multicolumn{2}{|c|}{ Flu Shots in past YearY/N } & 4485 & 40.6 & $=0001$ & 00160 \\
\hline & Non-Hispanic & 9114 & 40.3 & & & & No & 5896 & 44.3 & 0001 & 0.0100 \\
\hline & Missing & 169 & 36.7 & & & \multirow{8}{*}{$\begin{array}{l}\text { Health } \\
\text { Center }\end{array}$} & 1 & 1576 & 27.3 & & \\
\hline \multirow[t]{4}{*}{ Language } & English & 8480 & 37.3 & \multirow{4}{*}{$<.0001$} & \multirow{4}{*}{0.0035} & & 2 & 3312 & 30.5 & $<0001$ & \\
\hline & Spanish & 837 & 71.9 & & & & 3 & 438 & 48.2 & & \\
\hline & Other & 994 & 65.1 & & & & 4 & 238 & 79.4 & & \\
\hline & Missing & 70 & 30.0 & & & & 5 & 773 & 51.0 & & \\
\hline \multirow[t]{7}{*}{ Race } & White & 8622 & 40.5 & & & & 6 & 2619 & 58.9 & & \\
\hline & African American & 570 & 41.1 & $<0001$ & & & 7 & 1246 & 47.1 & & \\
\hline & Asian American/ & 744 & 60.6 & & & & 8 & 179 & 40.8 & & \\
\hline & & & & & & Community Vi & igns & & & & \\
\hline & Native American & 81 & 44.4 & & & GINI Income & 25th quartile & 1602 & 45.9 & $=0001$ & \\
\hline & Mixed race/Other & 51 & 31.4 & & & $\begin{array}{l}\text { Inequality } \\
\text { Ratio }\end{array}$ & $50 \%$ quartile & 2918 & 38.0 & . & \\
\hline & Unknown/Missing & 313 & 66.8 & & & & $75 \%$ quartile & 1457 & 40.9 & & \\
\hline Insurance & Medicaid & 3009 & 44.4 & & & & Missing & 4404 & 45.3 & & \\
\hline & Medicare & 3370 & 34.3 & $<.0001$ & 0.0011 & Unemploy- & 25th quartile & 2978 & 36.0 & & \\
\hline & Uninsured & 2178 & 65.5 & & & & $50 \%$ quartile & 4864 & 45.9 & $<.0001$ & \\
\hline & Commercial & 1824 & 28.5 & & & & $75 \%$ quartile & 2417 & 44.5 & & \\
\hline Household & $<14,999$ & 4493 & 46.0 & & & & Missing & 122 & 45.9 & & \\
\hline & $15,000-29,000$ & 1840 & 47.9 & $<.0001$ & & College & 25th quartile & 2190 & 48.5 & & \\
\hline & $30,000-44,999$ & 559 & 39.7 & & & & $50 \%$ quartile & 5388 & 42.3 & $<0001$ & \\
\hline & 45,000 - 59,999 & 245 & 30.6 & & & & $75 \%$ quartile & 2683 & 38.7 & & \\
\hline & $>60,000$ & 410 & 22.4 & & & & Missing & 120 & 46.7 & & \\
\hline & Unknown & 2834 & 38.8 & & & Pop & 25th quartile & 2444 & 38.1 & & \\
\hline Number of & 1 & 1671 & 37.8 & $<0001$ & 0.0497 & Density & $50 \%$ quartile & 5118 & 42.1 & $<.0001$ & \\
\hline in Past Year & $2-5$ & 5781 & 44.0 & & & & $75 \%$ quartile & 2700 & 47.9 & & \\
\hline & $6+$ & 2929 & 43.1 & & & & Missing & 119 & 47.1 & & \\
\hline Chronic Heal & $\mathrm{h}$ Conditions & & & & & 1 mile & Yes & 7974 & 43.8 & $<.0001$ & \\
\hline & \begin{tabular}{r|} 
Dlabetes (Iype II) \\
No
\end{tabular} & $\begin{array}{c}981 \\
9400\end{array}$ & $\begin{array}{l}51.4 \\
41.8\end{array}$ & $<.0001$ & & & No & 2407 & 39.2 & & \\
\hline & Depression & 2388 & 40.5 & & & Urban Rural & Rural & 2274 & 36.4 & & \\
\hline & No & 7993 & 43.4 & .0001 & & & Urban & 3071 & 35.8 & $<.0001$ & \\
\hline & Substance Abuse & 128 & 46.1 & & & & Cluster & 5036 & 49.9 & & \\
\hline & No & 10253 & 42.7 & 0.9020 & & ED Visits & 25th quartile & 2265 & 45.2 & & \\
\hline & & & & & & & $50 \%$ quartile & 4392 & 49.2 & $<.0001$ & \\
\hline & & & & $\begin{array}{l}\text { titicel } \\
\text { offel }\end{array}$ & Pas & & $75 \%$ quartile & 3692 & 33.6 & & \\
\hline lu Sho & st Year & & & & & & Missing & 32 & 46.9 & & \\
\hline
\end{tabular}

